\title{
Effect of Sediment Supply on Morphodynamics of Free Alternate Bars: Insights from Hydrograph Boundary Layer
}

\author{
Huang Dai ${ }^{1, *}$, Toshiki Iwasaki ${ }^{2}$ (I) and Yasuyuki Shimizu ${ }^{2}$ \\ 1 Graduate School of Engineering, Hokkaido University, Sapporo 0608628, Japan \\ 2 Faculty of Engineering, Hokkaido University, Sapporo 0608628, Japan; tiwasaki@eng.hokudai.ac.jp (T.I.); \\ yasu@eng.hokudai.ac.jp (Y.S.) \\ * Correspondence: daihuangdd@outlook.com; Tel.: +81-070-2427-6263
}

Citation: Dai, H.; Iwasaki, T.;

Shimizu, Y. Effect of Sediment Supply on Morphodynamics of Free Alternate Bars: Insights from Hydrograph Boundary Layer. Water 2021, 13, 3437. https://doi.org/ $10.3390 /$ w13233437

Academic Editors: Sándor Baranya and Nils Ruther

Received: 27 October 2021

Accepted: 30 November 2021

Published: 4 December 2021

Publisher's Note: MDPI stays neutral with regard to jurisdictional claims in published maps and institutional affiliations.

Copyright: (c) 2021 by the authors. Licensee MDPI, Basel, Switzerland. This article is an open access article distributed under the terms and conditions of the Creative Commons Attribution (CC BY) license (https:/ / creativecommons.org/licenses/by/ $4.0 /)$.

\begin{abstract}
Sediment supply plays an essential role in river morphology. However, the specific impact of sediment supply on river morphology is not apparent. According to the hydrograph boundary layer (HBL) concept, upstream riverbed changes caused by the imbalance between sediment supply and the capacity can propagate only a limited length and have a negligible effect on the riverbed beyond such a short length. We performed a two-dimensional morphodynamic calculation to test the concept of HBL, which was proposed under a one-dimensional simulation, meaning that the concept of HBL is still valid for plane changes in river morphology. We employed an unsteady flow with equilibrium or constant sediment supply in a straight, modeled gravel-bedded channel with an unerodible bank to simulate alternate bar morphodynamics. The results show that regardless of the sediment supply condition, the alternate bar features formed downstream of the HBL are considerably similar. This suggests that sediment disturbance at the upstream end has a negligible effect on the mobile-bed dynamic processes, including alternate bar formation and development downstream of the HBL.
\end{abstract}

Keywords: alternate bars; sediment transport; sediment supply; hydrograph boundary layer; gravel-bed rivers; numerical simulation

\section{Introduction}

Catastrophic flood events result in intense sediment transport and subsequent changes in river morphology, causing water and sediment-related disasters. For instance, riverbank erosion, levee collapse, and the movement of sandbars lead to urban flooding [1,2], road damage $[3,4]$, and bridge failure $[5,6]$. Therefore, a better understanding of the river morphodynamics and the factors controlling the system is essential for managing rivers and their floodplain environment and mitigating flood risks.

The river morphologies and their dynamics are influenced by numerous physical and environmental factors such as water discharge [7], bed slope [8], grain size [9], anthropogenic stresses [10], and sediment supply [11]. Among these factors, sediment supply plays a vital role because the imbalance between sediment supply from the upstream of river and sediment transport capacity causes bed aggradation or degradation in the downstream reach and controlling sediment transport features and overall river morphologies. For instance, Constantine et al. investigated the relationship between the sediment supply rate and meander migration rate in the Amazon River basin [12], and a strong positive correlation between these factors was observed. Stähly et al. studied the reservoir sediment ejection process in the Sarine floodplain [13]. Before the ejection, the downstream alternate bar disappeared because the block of the dam considerably reduced the sediment supply. Sediment ejection events extensively restored the formation of the downstream alternate bar. These studies clearly show that an inseparable relationship exists between sediment supply and river morphodynamics. 
However, despite the common knowledge regarding the importance of sediment supply to river morphodynamics, there are still deficiencies in understanding the scale and intensity of the impact from the imbalance between sediment supply and the capacity transport rate. For example, the Mississippi Delta has been suffering significant drowning, and the decline of the sediment transport rate from the upper Mississippi River due to dam construction is thought to be one of the causes [14]. Nittrouer and Viparelli [15], however, investigated the sediment transport rate in the Mississippi River and highlighted that the downstream sediment transport rate did not decline significantly despite dam construction, which is far upstream from the river mouth. This is because upstream degradation of the riverbed causes the sand to be supplied to the downstream instead of the sediment supply from the upper reach. Gaeuman et al. studied the response of the Duchesne River flow and sediment reduction caused by water development in the 1920s [16]. The results show that it took approximately 30 years for a $14 \mathrm{~km}$ channel to restore stability. The results show that the elevation change due to sediment supply conditions is closely related to the distance from the source. Such processes can be described as translation (or advection): i.e., dispersion of the sediment wave [17], and the importance of these two factors determines the effectiveness of the sediment source. These studies indicate that even though the sediment supply plays an important role in downstream river morphodynamics, we must consider the effective temporal and spatial scales of the sediment supply to the downstream environment.

In this study, we focus on the role of sediment supply in the downstream morphological changes in gravel-bed rivers during flood events. In this regard, Wong and Parker [18] proposed an important concept called the hydrograph boundary layer (HBL). They performed simple movable bed experiments and numerical simulations under cycled hydrographs and a constant sediment feed rate. Under these conditions, the upstream riverbed is forced to undergo repeated aggradation/degradation due to the imbalance between the constant sediment feed rate and the transport capacity, which is determined by the hydrograph. However, the bed elevation responds to the hydrograph only in a specific reach near the sediment feed point, indicating that upstream bed fluctuation can travel a short distance. This short river reach, which is affected by the upstream sediment imbalance, is termed as the hydrograph boundary layer (HBL), and in the downstream of HBL, the mobile-bed equilibrium, which indicates no bed elevation change, is achieved. This sediment feed condition is unlikely to occur in natural streams; however, this concept is helpful for a clear understanding of how the riverbed change caused by the imbalance between sediment feed and the capacity rate can propagate to the downstream river reach in a single flood event. So far, studies have been conducted based on the concept of HBL. Parker et al. tested several variables, such as hydrograph duration, grain size distribution, and bed slope, to determine their influence on the HBL. An et al. [19] applied the HBL theory to a massive sediment supply into a river caused by an earthquake to determine how the riverbed will react under such sediment supply conditions.

These studies shed some critical light on understanding the relationship between sediment feed conditions and river responses; however, further studies and discussions are required for a more complex situation. For example, An et al. [20] pointed out a breakdown of the HBL concept in poorly sorted sediment cases, showing that low-amplitude bedload sheets can travel beyond the HBL. The other limitation of this concept is that most previous studies were performed under one-dimensional flow and sediment transport fields. In other words, even though mobile-bed equilibrium can be achieved downstream of the $\mathrm{HBL}$, it remains unclear whether the upstream effect has no role in complex morphological elements such as sand bars or channel meandering. The 2D river morphologies can also be affected by sediment supply conditions [21,22], but an interpretation of the effect of sediment supply on river morphodynamics is not always straightforward because of the difficulty of sediment transport measurement in the field. Therefore, the concept that HBL is also valid for $2 \mathrm{D}$ cases must be focused on to better understand the effect of sediment supply on downstream morphodynamics. 
In this study, a series of two-dimensional morphodynamic calculations regarding the alternate bar development with the HBL effect were conducted. According to the concept of HBL, the sediment transport rate outside the HBL region will reach equilibrium because there is almost no change in the bed elevation. It can be inferred from the properties of the HBL that if two cases have the same cycled hydrograph but different sediment supply conditions, more specifically, constant and equilibrium feed rate, the river morphology outside the HBL may not change as well as the bed elevation. However, this study aimed to determine how HBL acts in two-dimensional cases and how river morphology responds to the imbalance of sediment supply during a flood event.

\section{Methods}

\subsection{Numerical Model}

We used the Nays2DH model [23], a two-dimensional morphodynamic model enclosed in the iRIC software [24]. This model has been applied to various morphodynamic phenomena in rivers [25], and the model can simulate the alternate bar morphodynamics focused on in this study $[26,27]$.

The flow model is an unsteady two-dimensional shallow water flow model. The governing equations of this model are written for a generalized coordinate system; however, for simplicity, here, we describe the governing equations in the Cartesian coordinate system:

$$
\begin{gathered}
\frac{\partial h}{\partial t}+\frac{\partial u h}{\partial x}+\frac{\partial v h}{\partial y}=0 \\
\frac{\partial u}{\partial t}+u \frac{\partial u}{\partial x}+v \frac{\partial u}{\partial y}=-g\left(\frac{\partial h}{\partial x}+\frac{\partial z}{\partial x}\right)-\frac{g n^{2} u \sqrt{u^{2}+v^{2}}}{h^{\frac{4}{3}}} \\
\frac{\partial v}{\partial t}+u \frac{\partial v}{\partial x}+v \frac{\partial v}{\partial y}=-g\left(\frac{\partial h}{\partial y}+\frac{\partial z}{\partial y}\right)-\frac{g n^{2} v \sqrt{u^{2}+v^{2}}}{h^{\frac{4}{3}}}
\end{gathered}
$$

where $x$ and $y$ are the downstream and transverse coordinates, $h$ is the water depth, $z$ is the riverbed elevation, $t$ is time, $u$ and $v$ are depth-averaged velocity components in the $x$ and $y$ directions, respectively, $\mathrm{g}$ is the gravitational acceleration, and $n$ is the Manning coefficient.

Because we focus on the morphodynamics of the gravel-bed river, we only consider bedload transport as a mode of sediment transport. The Meyer-Peter and Müller formula was used here, and the sediment was considered to have a uniform grain size. The sediment transport model used was as follows:

$$
\begin{gathered}
q_{b s}=8\left(\tau_{*}-\tau_{* c}\right)^{\frac{3}{2}} \sqrt{s g d^{3}} \\
q_{b n}=q_{b s}\left(\frac{u_{b n}}{V}-\sqrt{\frac{\tau_{* c}}{\mu_{s} \mu_{k} \tau_{*}}} \frac{\partial z}{\partial n}\right)
\end{gathered}
$$

where $\tau *$ is the Shields number, $\tau_{*}$ is the critical Shields number, $s$ is the submerged specific gravity of the sediment, $d$ is the grain size of the bed material, $q_{b s}$ and $q_{b n}$ are the bedload transport rates in the $x$ and $y$ directions, respectively, $u_{b n}$ is the flow velocity near the riverbed in the $n$ direction, $V$ is the composite velocity near the riverbed, and $\mu_{s}$ and $\mu_{k}$ are the static friction coefficient and dynamic friction coefficient, respectively.

The following Exner equation updates the bed elevation:

$$
(1-\lambda) \frac{\partial z}{\partial t}+\frac{\partial q_{b x}}{\partial x}+\frac{\partial q_{b y}}{\partial y}=0
$$

where $\lambda$ is the void ratio of the bed. 


\subsection{Computational Conditions}

As a case study, we simplified the condition of the Otofuke River, which is a typical gravel-bed river [28]. This river was affected by a large flood in 2011, which caused significant development of sand bars and subsequent channel meandering; therefore, this is a relevant example for the 2D river morphodynamics in gravel-bed rivers. The channel for the calculation is straight with a width of $70 \mathrm{~m}$ and length of $21 \mathrm{~km}$, and the slope of the initial riverbed was set to 0.005 . A Manning roughness coefficient of $0.028 \mathrm{~s} / \mathrm{m}^{1 / 3}$ and a uniform particle size of $40 \mathrm{~mm}$ were used. This is the simplified channel configuration of the main channel of the Otofuke River.

The observed hydrograph is modeled as a simple triangle-shaped hydrograph; that is, the water discharge linearly increases from 100 to $600 \mathrm{~m}^{3} / \mathrm{s}$ within $20 \mathrm{~h}$ and decreases from 600 to $100 \mathrm{~m}^{3} / \mathrm{s}$ linearly within the next $20 \mathrm{~h}$, which makes the whole cycle of $40 \mathrm{~h}$, as shown in Figure 1.

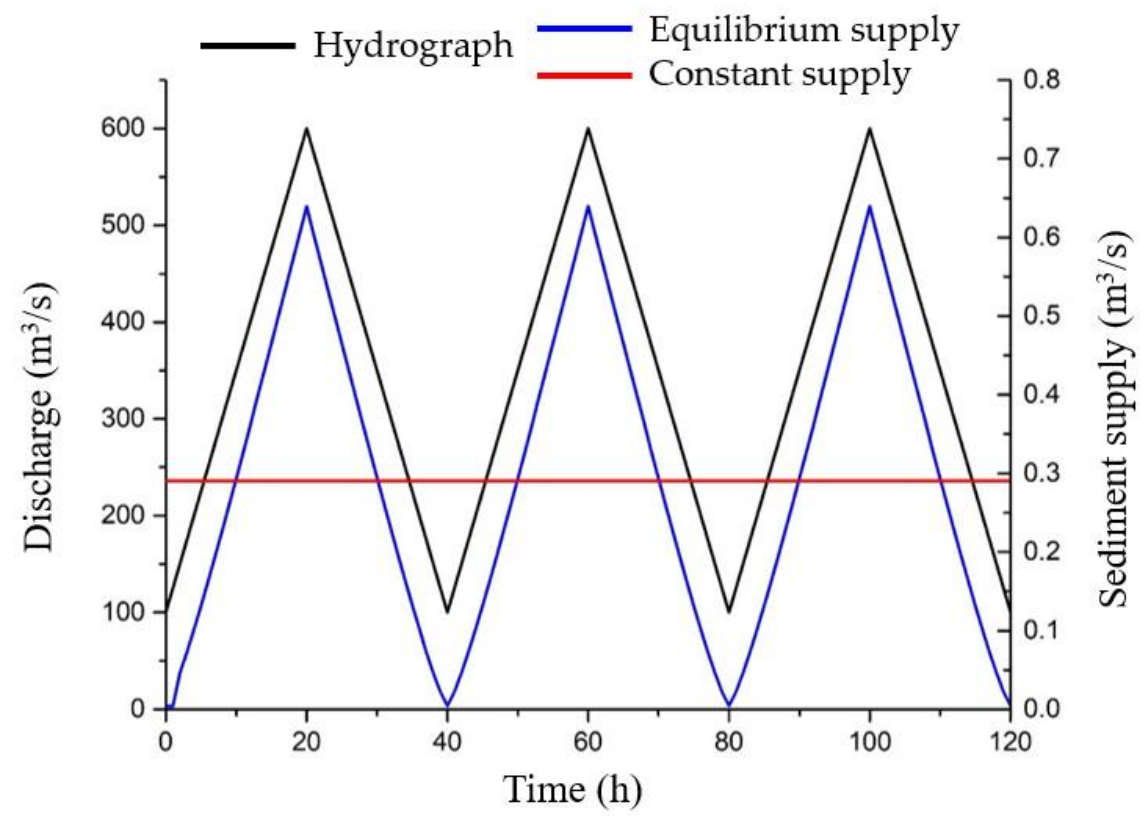

Figure 1. Hydrograph and sediment supply conditions used for the base calculation (Case 1). The three hydrographs are shown here as an example, but in the calculation, 50 hydrographs were obtained.

We set two sediment supply conditions, namely equilibrium and constant sediment feed conditions. The equilibrium condition provides the equilibrium sediment transport rate calculated using the flow parameters from the upstream end. This feed rate is the sediment transport capacity of this modeled river, and the supply rate depends on the hydrograph, as shown in Figure 1. Because the feed rate is equivalent to the transport capacity, the bed elevation at the upstream end does not change over time under this condition.

The constant-feed condition is intended to obtain the hydrograph boundary layer at the upstream end [18]. The constant-feed rate obtained from the upstream end is a type of averaged sediment transport rate over the hydrograph, so that the bed elevation at the upstream end varies over the hydrograph, but the average bed elevation over the hydrograph does not change. This feed condition makes the bed slope remain constant throughout the calculation, and the total sediment supply rate under this condition becomes the same as the equilibrium condition. Note that we slightly modified the original model of the Nays2DH code to provide a constant sediment feed rate from the upstream end.

The difference between the two conditions is only the persistent bed fluctuation over the hydrograph; the former case provides no bed variation, whereas the latter condition provides the fluctuation of bed elevation caused by the imbalance between the sediment 
transport capacity and the sediment feed rate. According to Wong and Parker [18], the bed fluctuation of the latter run propagates downstream but has an influential role within the limited river reach from the upstream end, that is, HBL; thus, there should be no difference in the morphodynamic features downstream of the HBL in both conditions. This is valid for 1D cases; however, in this study, we investigated whether this concept is still valid for the 2D morphodynamic phenomena developed beyond HBL, such as the formation and development of alternate bars that take place far downstream from a sediment source into the river.

In addition to this hydrograph condition, as a parameter study, we performed two additional computations by changing the features of the hydrograph but retaining the triangular shape. The computational conditions above are defined as Case 1, and in Case 2, a longer hydrograph duration (i.e., $80 \mathrm{~h}$ ) with the same peak discharge as Case 1 was used. In Case 3, a higher peak discharge (i.e., $1200 \mathrm{~m}^{3} / \mathrm{s}$ ) with the same hydrograph duration as Case 1 was adopted, as summarized in Table 1 . The large ensemble climate and runoff calculations have been used to predict this kind of hydrograph variation in past and future climates [29-31], so the condition of this numerical experiment is realistic.

Table 1. Hydrograph duration and variation in the numerical experiment.

\begin{tabular}{ccc}
\hline & Hydrograph Duration & Discharge Variation \\
\hline Case 1 & $40 \mathrm{~h}$ & $100-600 \mathrm{~m}^{3} / \mathrm{s}$ \\
\hline Case 2 & $80 \mathrm{~h}$ & $100-600 \mathrm{~m}^{3} / \mathrm{s}$ \\
\hline Case 3 & $40 \mathrm{~h}$ & $100-1200 \mathrm{~m}^{3} / \mathrm{s}$ \\
\hline
\end{tabular}

We obtained 50 hydrographs for all calculations. This numerical experiment was intended to understand how the hydrograph duration and peak discharge influence the HBL characteristics and the downstream sand bar characteristics beyond the HBL.

\section{Results}

\subsection{Two-Dimensional Study of the Hydrograph Boundary Layer: Alternate Bar Formation}

Figure 2 shows the bed elevation change along the right bank after 25 hydrographs are provided in Case 1 with a constant sediment feed condition. Figure 2a,b illustrate the 1D morphodynamic features in the entire calculation at reach at the lowest and peak discharges (i.e., 100 and $600 \mathrm{~m}^{3} / \mathrm{s}$, respectively). The structured bed variation observed in the downstream reach $(5-21 \mathrm{~km})$ corresponds to alternate bars. At the upstream end, the lowest discharge causes the highest elevation change (i.e., aggradation), whereas the peak discharge provides the lowest elevation change (i.e., degradation). This elevation change is caused by the imbalance between the sediment feed rate and the sediment transport capacity; when the water discharge is low (high), the sediment feed rate is larger (smaller) than the sediment transport capacity, resulting in aggradation (degradation). This elevation difference at the upstream end within a single hydrograph is not small, approximately $2 \mathrm{~m}$, which is almost the same as the bar height developed at the downstream reach. However, this bed elevation change enables the propagation to only short distances such as $1.5 \mathrm{~km}$ from the source, that is, the upstream end, as shown in Figure 2. This feature is precisely what Wong and Parker obtained in their 1D morphodynamic calculation (i.e., $\mathrm{HBL}$ ); thus, this result clearly shows that the HBL also formed in our 2D simulation. This figure also demonstrates that an alternate bar was developed outside this HBL zone. There is a reach between these two zones where no elevation fluctuation exists or bars are formed. Hereafter, we refer to these three zones as the HBL zone (0-1.3 km), buffer zone (1.3-5 km), and bar zone ( $5 \mathrm{~km}$, downstream end). 
(a)

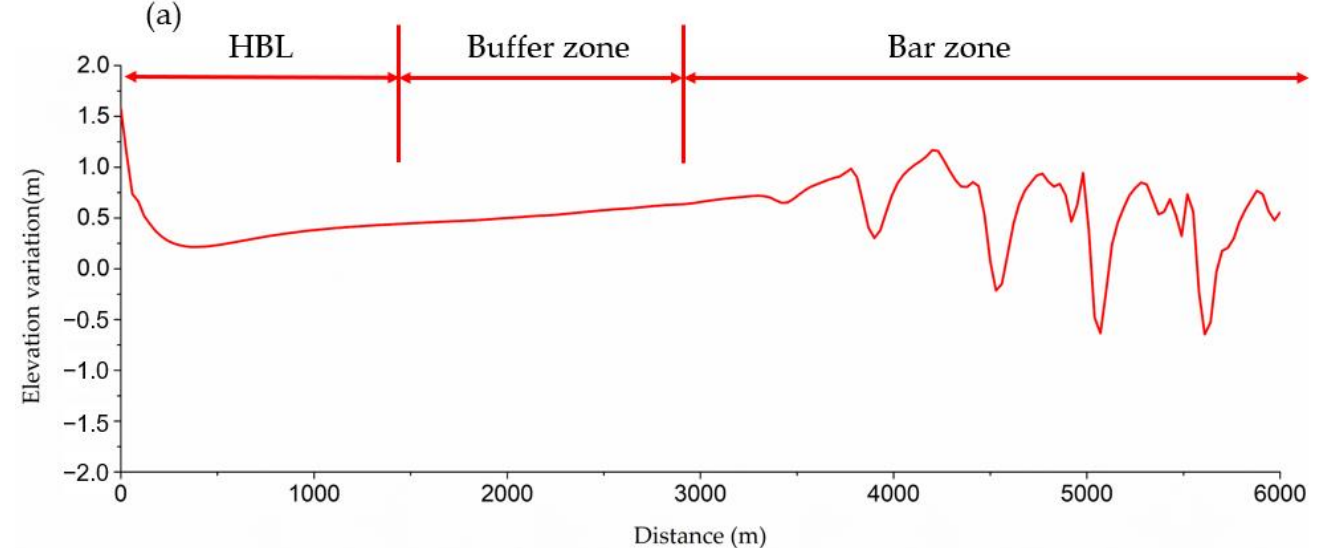

(b)

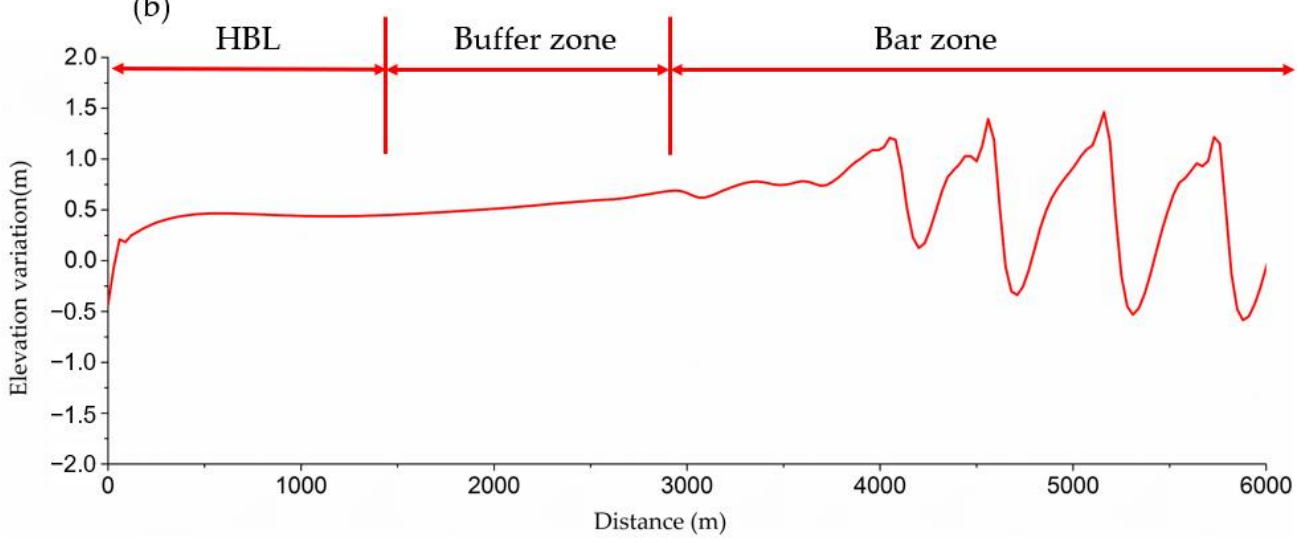

Figure 2. Bed elevation change along the right bank $6000 \mathrm{~m}$ upstream after 25 hydrographs in the case of constant sediment feed condition. (a) At lowest discharge. (b) At peak discharge.

Figures 3 and 4 compare the 1D bed profiles of Case 1 between the equilibrium and constant sediment feed conditions. Because the sediment feed rate is equivalent to the capacity rate, there is no bed elevation change at the upstream end in the equilibrium feed condition. Except for this difference, the other morphodynamic features, namely downstream bar characteristics and emerging points of the bars, are quite similar in both runs, regardless of the sediment feed condition. The only difference is the phase difference of the trains of alternate bars between the two runs. To highlight the similarity of the alternate bar characteristics more clearly, Figure 5 shows the elevation variation comparison at the right bank in both runs by removing the phase difference. Regardless of the discharge (i.e., the low or high discharge states), the bar height and wavelength in both runs were almost the same.

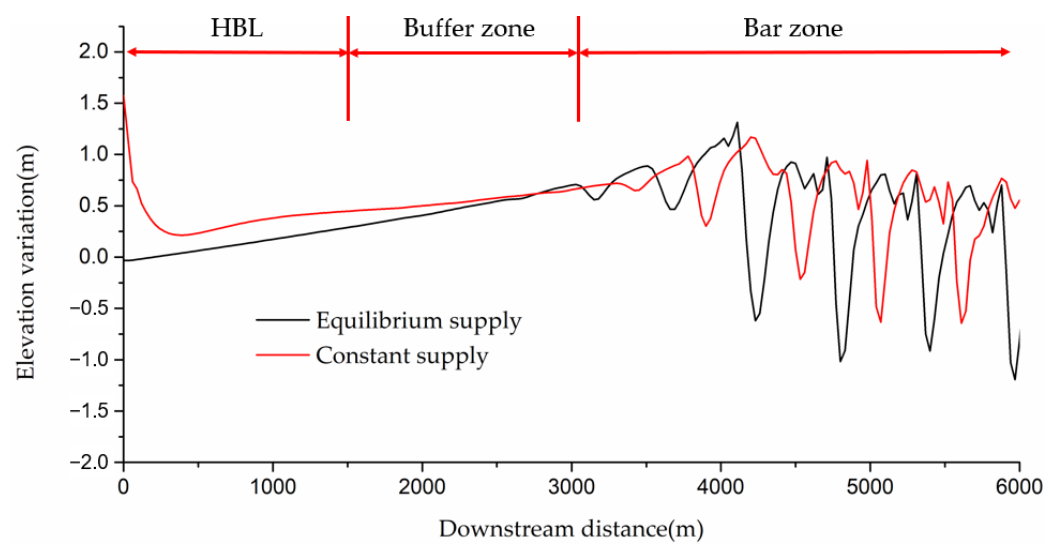

Figure 3. 1D bed profiles of Case 1 along the right bank $6000 \mathrm{~m}$ upstream after 25 hydrographs. 


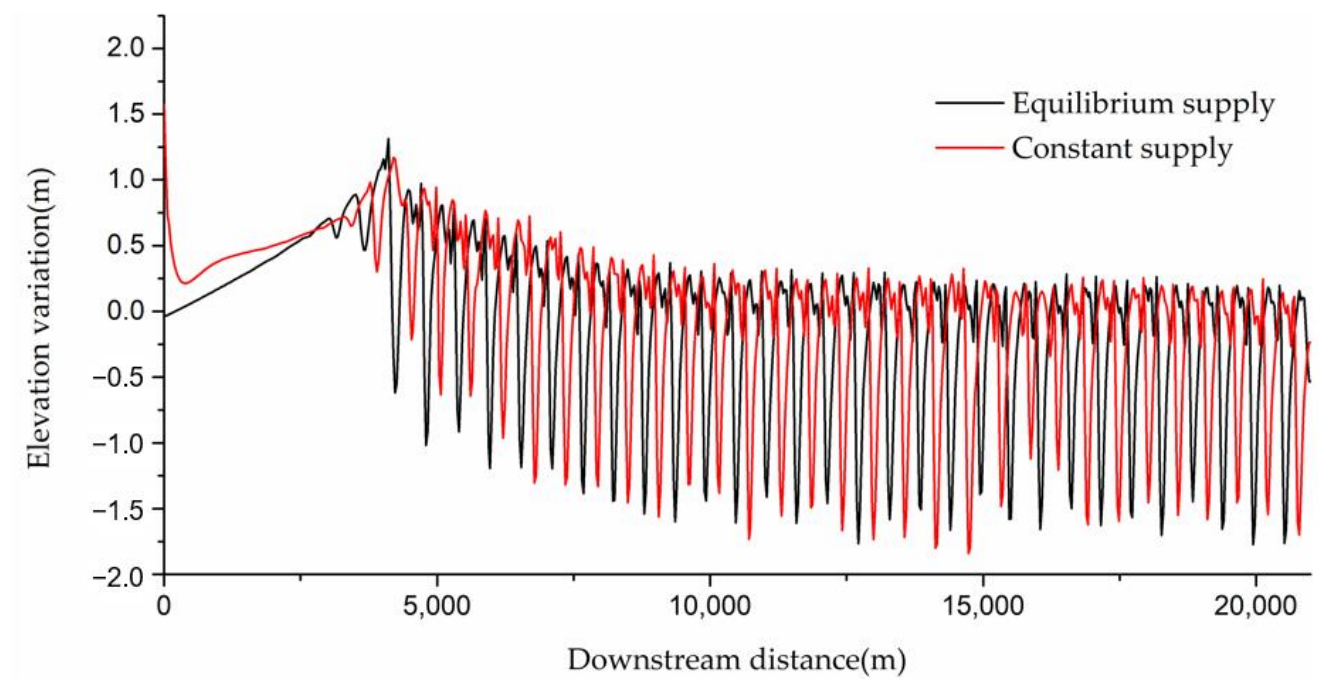

Figure 4. Elevation variation comparison at the right bank in both runs after 25 hydrographs.

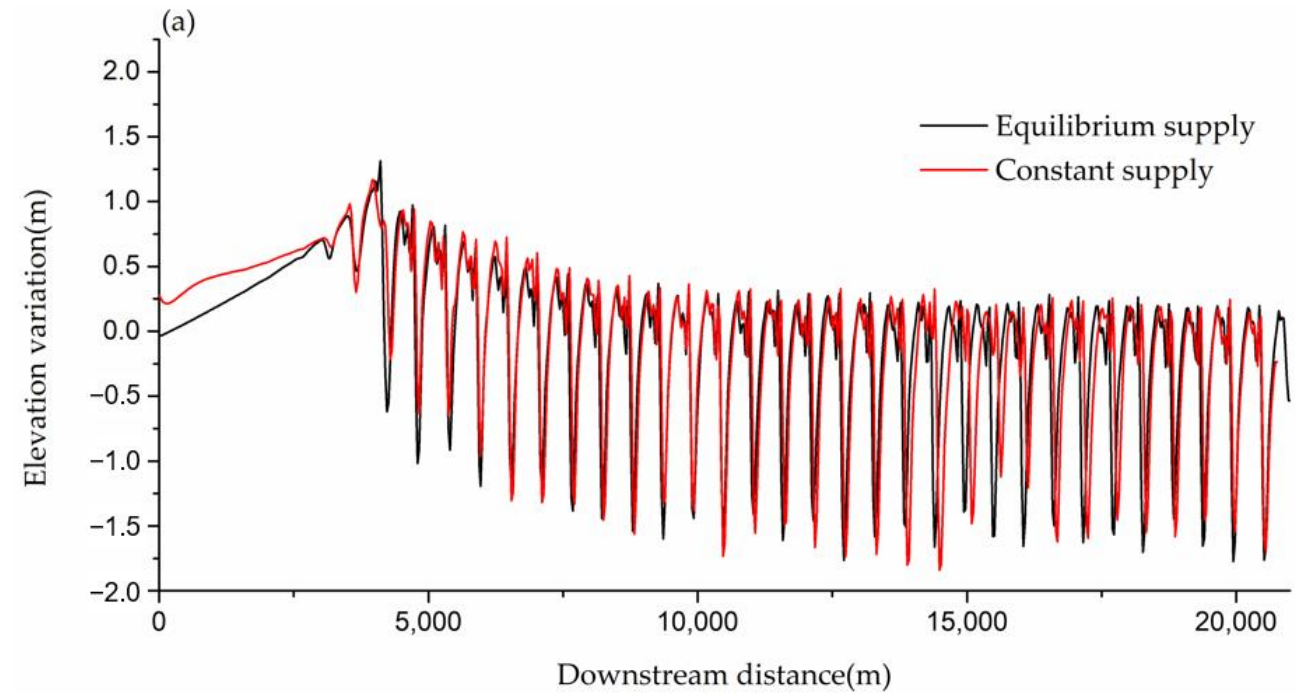

(b)

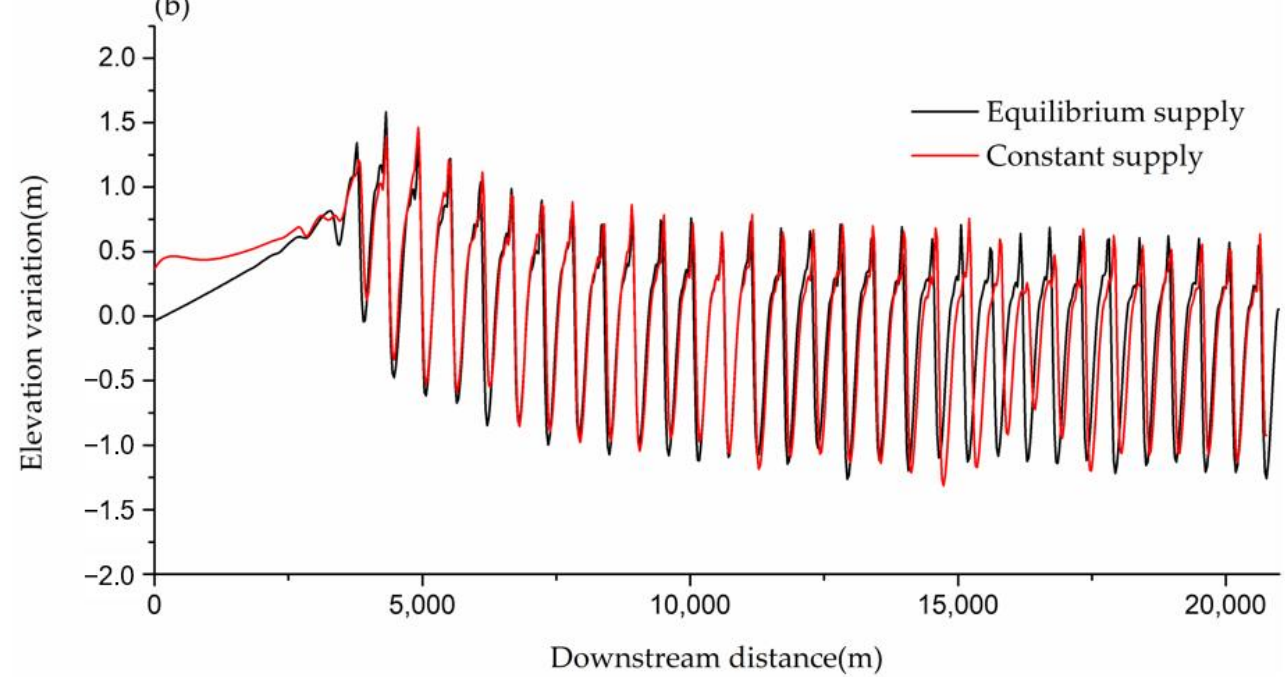

Figure 5. Elevation variation comparison at the right bank in both runs after removing the phase difference: (a) At lowest discharge. (b) At peak discharge. 
Figure 6 shows the 2D top view of the bar area for a better illustration of the similarity and difference in spatial features of the alternate bar shape. Because the width-length ratio of this computational reach is too small, the downstream distance from approximately $10 \mathrm{~km}$ to $12 \mathrm{~km}$ was taken as a sample. As also observed in this figure, the alternate bar characteristics (not only the wave height and wavelength but also the 2D shape) are almost identical at the same time points. Meanwhile, the migrating processes were also similar in both cases; the bar moved almost the same distance downstream within $20 \mathrm{~h}$.

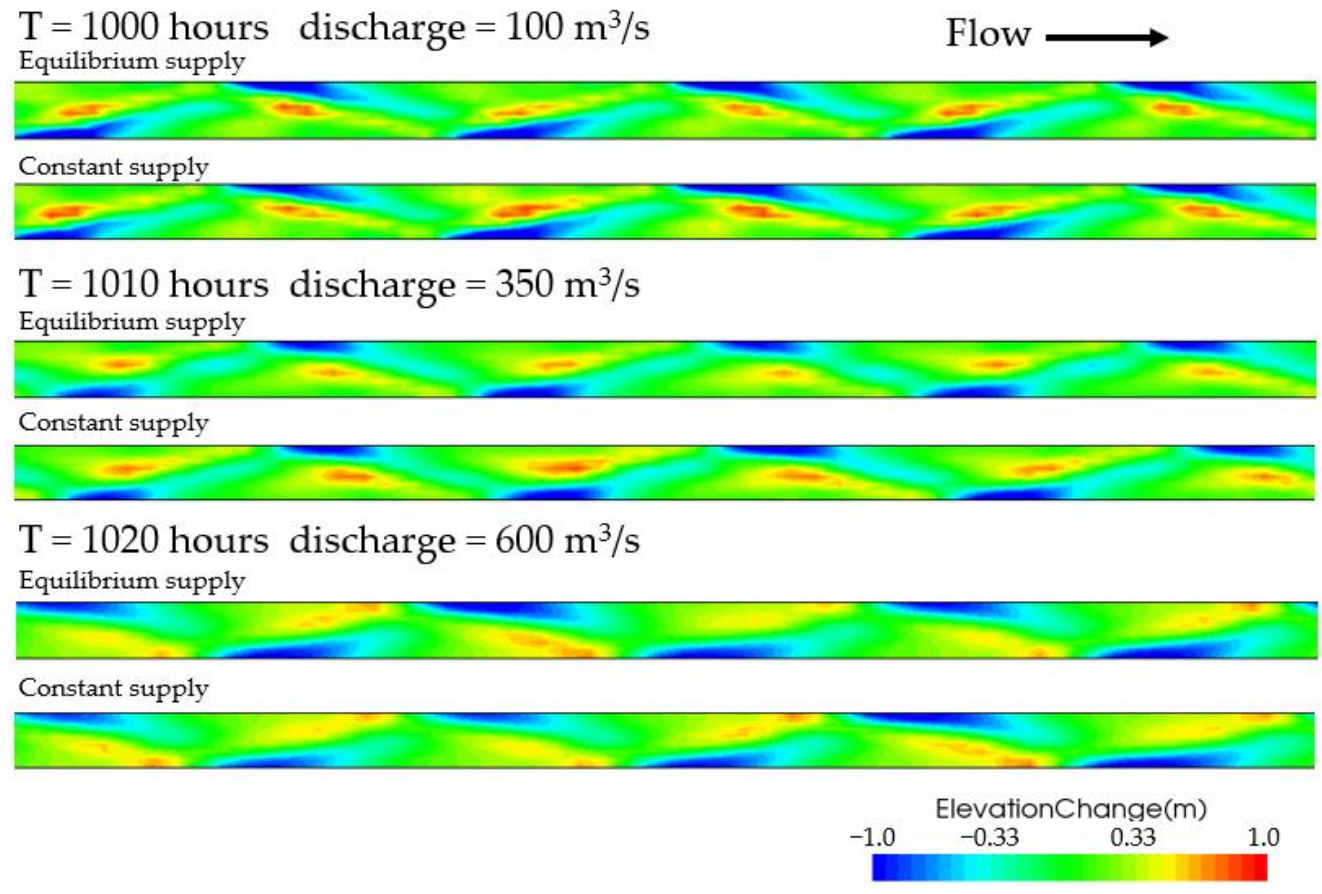

Figure 6. 2D top view of alternate bars simulated in Case 1.

The discussion above is based on specific time points and the distance of the channel. For a more qualitative evaluation of the results, the bar characteristics over the entire calculation time must be overviewed. We apply the fast Fourier transform analysis to the time series of 1D bed elevation changes (e.g., Figure 2). Figure 7 shows the FFT analysis result, indicating that the $2 \mathrm{D}$ contour map of the spectrum power in the time-wavelength domain in Case 1. As expected from the quantitative comparison above, this diagram seems very similar in both runs, suggesting that the bar characteristics (e.g., dominant wavelength) and their temporal changes are quantitatively similar. However, after approximately $1500 \mathrm{~h}$, the dominant bar wavelength obtained in the constant sediment feed condition extends to approximately $600 \mathrm{~m}$. Figure 8 shows the elevation change along the right bank after $1800 \mathrm{~h}$. This comparison shows that the bar characteristics are almost similar in the upper bar area (i.e., the downstream distance is $3-13 \mathrm{~km}$ ). This is also seen in the spectrum diagram (Figure 7), which shows a second peak in the spectrum at a wavelength of $550 \mathrm{~m}$ under constant-feed conditions. However, at the further downstream reach, the elevation variation and wavelength increase, thus increasing the amplitude and period in the FFT analysis, which makes the dominant wavelength $600 \mathrm{~m}$ in the constant-feed case. In contrast, the bar characteristics in the equilibrium feed case seem somewhat spatially consistent, leading to only a single, strong peak in the spectrum diagram. 

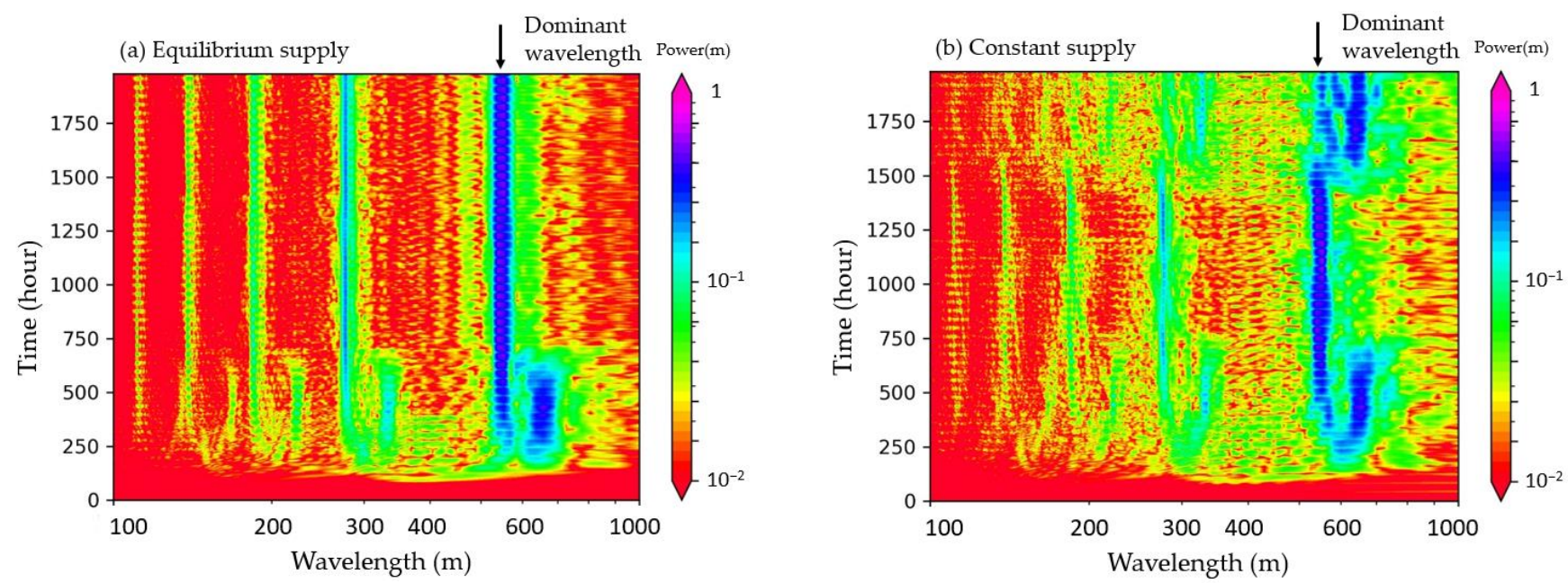

Figure 7. FFT analysis of dominant wavelength in case 1: (a) Equilibrium sediment supply. (b) Constant sediment supply.

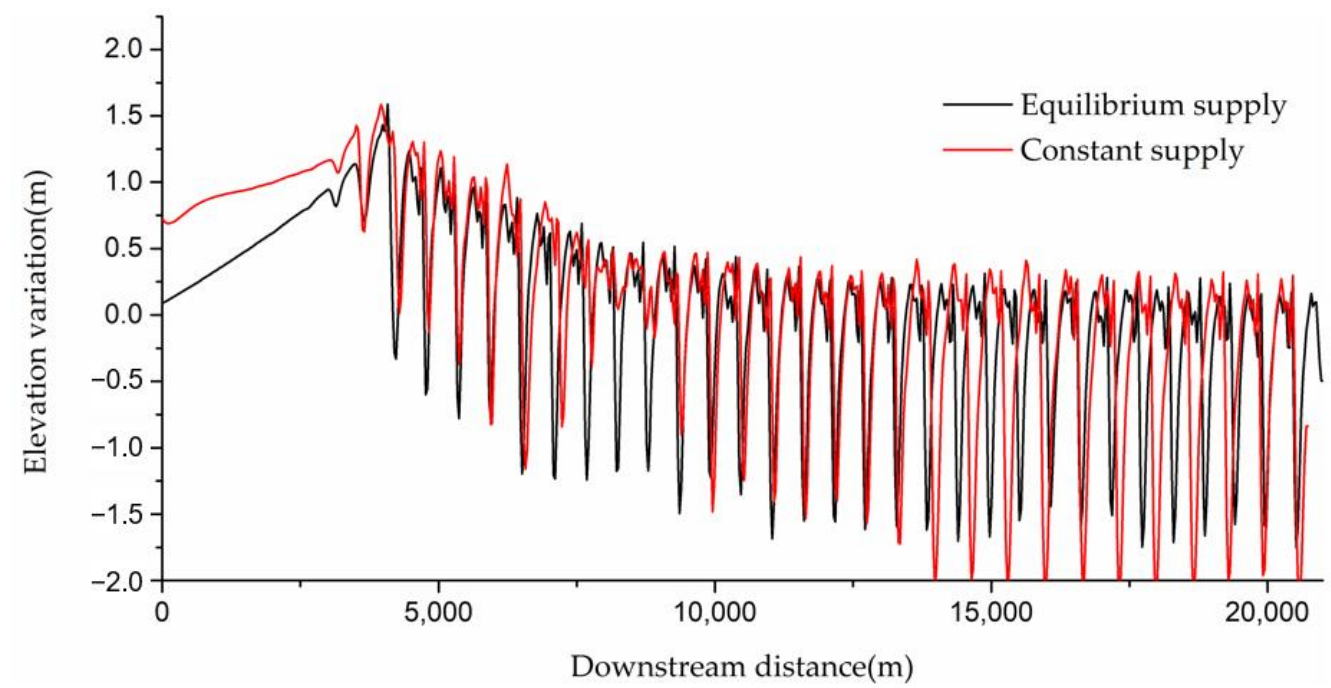

Figure 8. Elevation variation comparison at the right bank in both runs after $1800 \mathrm{~h}$ removed phase difference.

The cause of this difference at a later time might be an increase in elevation in the buffer zone. To investigate this, three specific points in three zones (i.e., $900 \mathrm{~m}, 2400 \mathrm{~m}$, and $9000 \mathrm{~m}$ downstream) were selected based on the results after removing the phase difference. In Figure 9, comparisons are made according to the elevation variation in these points. Both runs show this elevation increase in the buffer zone; however, this feature is more significant in the constant-feed case. This makes the slope steeper, and this difference may affect the bar characteristics. This bed elevation increase is observed after bar development, so that the alternate bar formed in the downstream reach has some roles in the upstream bed elevation change. Generally, alternate bars have a negligible effect on the flow resistance, but they play a role in the sediment transport rate [32]. These effects may affect the width-averaged bedload transport rate, causing some deposition (or erosion) upstream of the alternate bars. This point must be investigated; however, this effect is essentially not related to sediment feed conditions. The bar characteristics are very similar in the early stage before the elevation increase in the buffer zone is not significant (i.e., $500 \mathrm{~h}$ ). In addition, even at a later stage, there is still a very similar bar area upstream. 

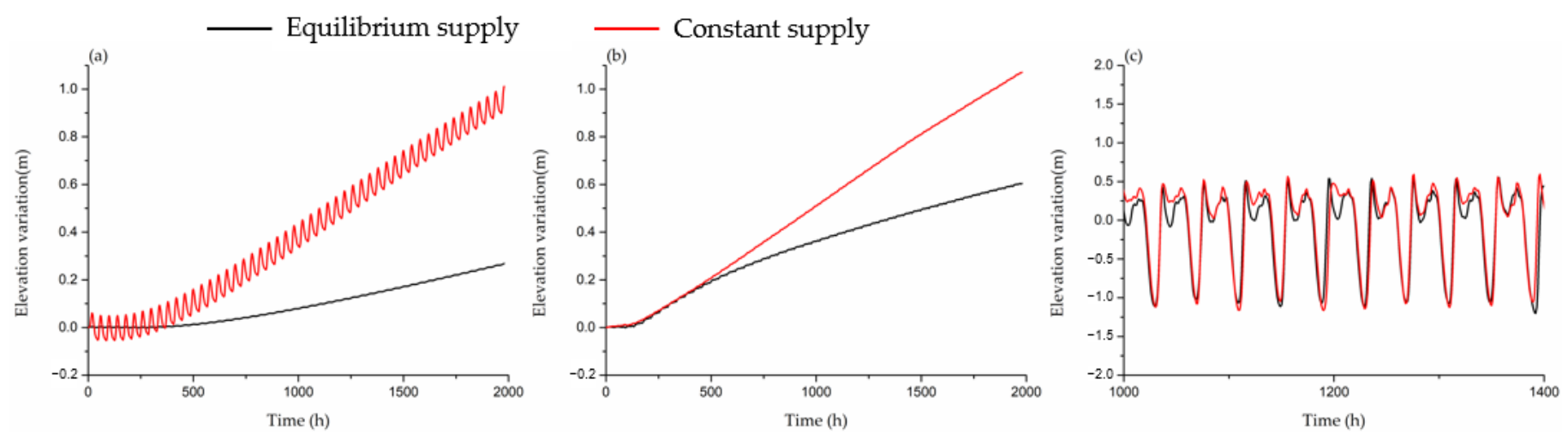

Figure 9. Elevation variation comparison of three specific points in three zones. (a) The point $900 \mathrm{~m}$ downstream in the HBL zone. (b) The point $2400 \mathrm{~m}$ downstream in the buffer zone. (c) The point at $9000 \mathrm{~m}$ downstream in the bar zone (i.e., to make the comparison clear, the time range from 1000 to $1400 \mathrm{~h}$ is selected).

In summary, regardless of the sediment supply condition, the alternate bar feature formed downstream of the HBL is quantitatively very similar. This suggests that the findings regarding HBL [18] are almost valid for dynamics of alternate bars developed beyond HBL, that is, sediment disturbance at the upstream end has a negligible effect on the mobile-bed dynamic equilibrium downstream of the HBL.

\subsection{Sensitivity Analysis}

We present two additional results, that is, Cases 2 and 3, to highlight the effect of hydrograph shape, more specifically, the hydrograph duration and peak discharge, on the HBL features and dynamics of alternate bars. Figure 10 shows the elevation variation at the upper reach of the channel under a constant sediment supply in each case to highlight the properties of the HBL. The two lines used in each case were chosen to show the highest and lowest bed profiles within the hydrograph. This figure clearly demonstrates that the longer and larger hydrograph extends the length of the HBL; this length is approximately $1.3,1.5$, and $1.8 \mathrm{~km}$ in Cases 1, 2, and 3, respectively.

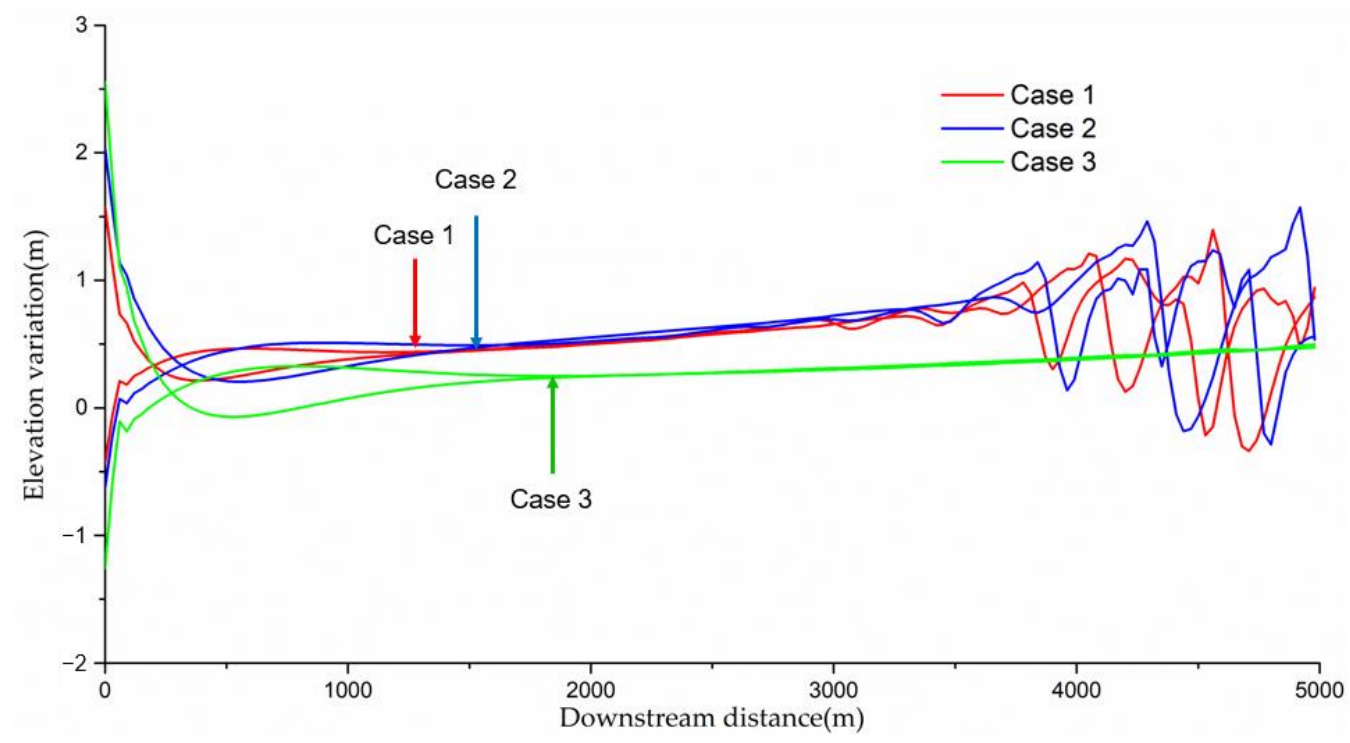

Figure 10. Elevation variation at the upper reach of the channel of Cases 1, 2, and 3 when discharge is maximum/minimum.

As shown in Figure 10, alternate bars are formed outside the HBL in Cases 2 and 3, so we again investigated the difference in the bar properties downstream of the HBL. Figures 11 and 12 demonstrate the temporal change in the spectrum power provided by 
the FFT analysis applied to the 1D bed profile in Cases 2 and 3. The bar properties, such as the dominant wavelength and time-dependent features, are different for each case. For instance, in Case 2, the dominant bar wavelength is approximately $720 \mathrm{~m}$ in both sediment feed conditions; however, there are several secondary peaks in the spectrum around the dominant one. In addition, the time-dependent features of such secondary peaks are relatively significant, indicating that the bar properties become less stable than those in Case 1. The FFT results for Case 3 indicate two clear peaks in the spectrum diagram. The corresponding dominant wavelengths were approximately 450 and $550 \mathrm{~m}$, respectively. Although the dominant wavelengths are similar between the two sediment feed conditions compared with Cases 1 and 2, the differences in the bar characteristics indicated by the FFT analysis in Case 3 are slightly more evident than those in Cases 1 and 2.
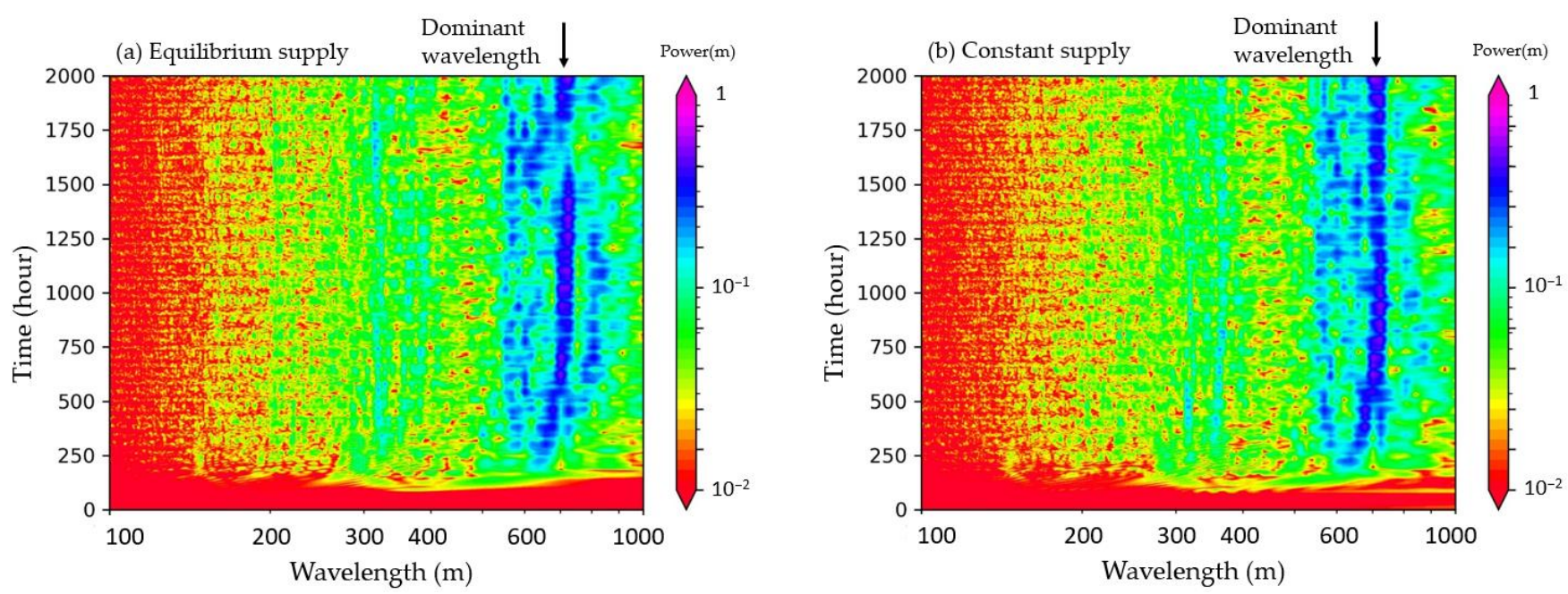

Figure 11. FFT analysis of the dominant wavelength in Case 2. (a) Equilibrium sediment supply. (b) Constant sediment supply.
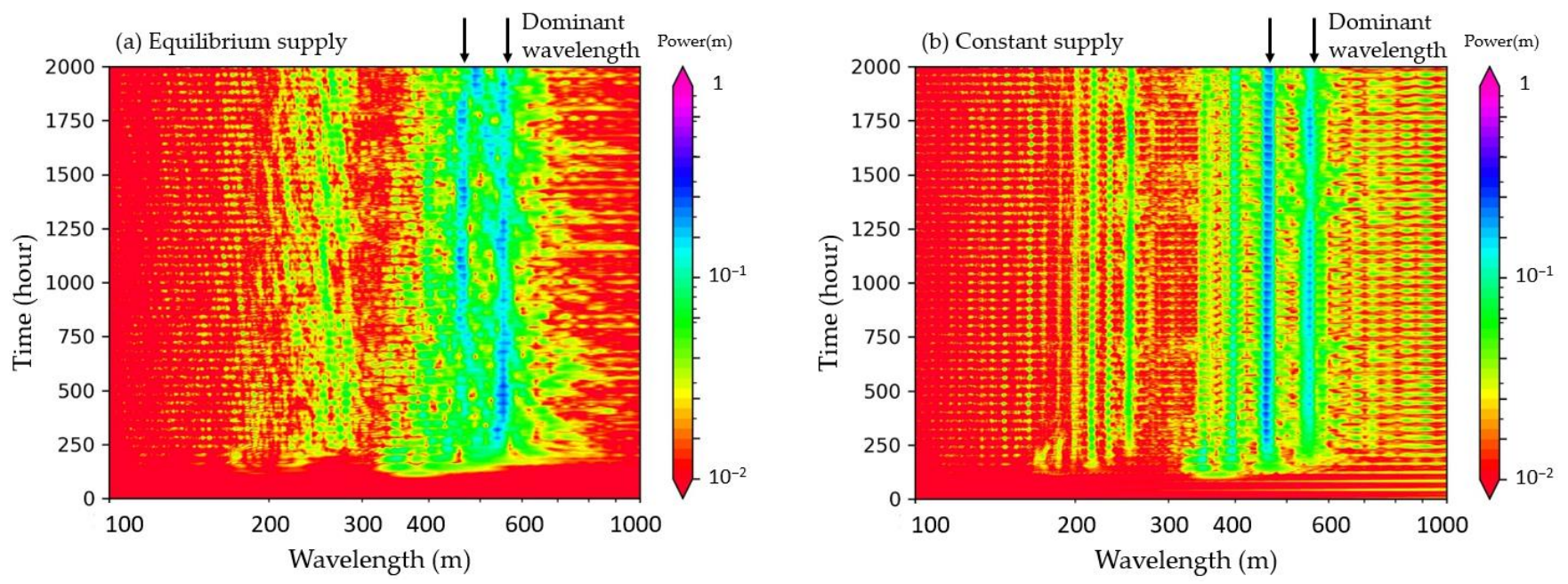

Figure 12. FFT analysis of dominant wavelength in Case 2. (a) Equilibrium sediment supply. (b) Constant sediment supply.

There are some differences in the characteristics of alternate bars formed outside the HBL, particularly time-dependent features, between equilibrium and constant sediment feed conditions. In Cases 2 and 3, HBL is more significant than Case 1, so this effect might be seen as a slight difference in the time-dependent features of the alternate bars. However, the spectrum diagram generally seems very similar regardless of the sediment feed conditions. The results may indicate that as long as the alternate bars develop far outside the HBL, the bed elevation change caused by the feed condition does not propagate 
beyond the HBL; the difference in bar properties between the two sediment feed conditions eventually becomes negligible.

\section{Discussion}

\subsection{Implications}

The present results indicate that the length of the HBL is an effective spatial scale of the additional sediment input into the river during a single flood event, so that the sediment supply condition in the upstream boundary has little effect on the river morphologies far downstream from the source. Numerous studies have suggested that massive sediment supply into rivers caused by, for instance, dam removal or landslides, causes reorganization of the river morphologies, grain size distribution, and environments [33,34]. This is inevitably valid for a specific river reach from the sediment source; however, at a more downstream reach, such as beyond the HBL, the effect of sediment disturbance will be very small or no longer measurable. In particular, in gravel-bed rivers, where sediment dispersion is dominant rather than in translation, the sediment pulse has a limited effect on downstream channel morphologies such as bar-pool structures $[35,36]$. This is what the concept of the HBL suggested, and in addition to the 1D mobile-bed equilibrium outside the HBL, the upstream sediment feed condition has a limited role in the 2D morphodynamics such as alternate bar dynamics focused herein at such a river reach. Because the effective length is limited, predicting the HBL length scale might be helpful for effective sediment replenishment works [37].

However, we must mention that the effective length scale of the sediment disturbance scaled by the HBL is short term, similar to the hydrograph scale, and is not applicable for long-term effects, such as a continuous decline in the sediment supply rate due to dam construction [38]. In this case, the upstream sediment condition eventually propagates far downstream by long-term flow-sediment transport processes. In addition, the transport feature of the sediment disturbance highly depends on its properties, such as the mass, size, and grain size of the sediment augmentation [39] and hydraulic conditions [40], so some of the sediment disturbance likely propagates beyond the HBL and affects the river morphology.

The increase in the hydrograph duration and peak discharge we tested in the sensitivity analysis (i.e., by a factor of 2 from the observed significant flood event in this river), is an extreme change in the hydrological perspective, but the difference in the HBL length caused by this extreme hydrograph difference is not significant. This might suggest that, practically speaking, the HBL length can be assumed as a constant in a single river (or some specific reach focused). Because this length is a type of adaptation length scale of the river subject to the imbalance between the sediment feed and the capacity within a single flood event, it will be useful to predict the length of the HBL through a simpler way. Wong and Parker [18] theoretically predicted this length using the linearized governing equation, as follows:

$$
\delta \sim\left[\frac{T_{h} q_{b f}}{(1-\lambda) S_{0}}\right]^{1 / 2}
$$

where $q_{b f}$ is the constant bedload transport rate, which achieves the mobile-bed equilibrium state over the hydrograph, $S_{0}$ is the bed slope of such an equilibrium state, and $T_{h}$ is the hydrograph duration. The conditions of our calculation obtained the right-hand side of Equation (7) as 454, 642, and $700 \mathrm{~m}$ for Cases 1, 2, and 3, respectively. Multiplying the factor 2.5 to these numbers is a good predictor for the $\delta$ we obtained (Figure 10). By verifying this equation this way, we might be able to use this predictor for non-linear systems as well. Again, the features of the HBL should be related to the intensity of the hydrograph and sediment condition [20] as well as the hydraulic conditions [40]. Therefore, this point needs to be investigated for different types of river reaches such as sand-bed or lowland rivers. 


\subsection{Limitations}

One of the limitations of our study was the assumption of a single grain size of the sediment. In gravel-bed rivers, the effect of graded sediment on sediment transport and morphodynamics is significant [20,41,42], which might have altered our findings. For example, An et al. [20] showed that low-amplitude bedload sheets can propagate long distances beyond the HBL in the case of poorly sorted graded sediment. The bar dynamics in the graded sediment case are more unstable than those in the case of uniform sediment [43]; therefore, it is likely that the low-amplitude bedload sheets or some small fluctuations caused by sediment feed conditions can drastically change the dynamics of the graded sediment sand bars.

This limitation is also critical in cases where suspended sediment transport should be considered [44]. The length scale of the suspended sediment transport is much longer than that of the bedload, so that the effect of sediment supply into the river can reach more downstream. Landslides or debris flow events bring finer sediment than those in the riverbed [45]; therefore, this type of sediment supply has a different role in the bedloaddominated condition. Our focus is on gravel-bed rivers, so this is beyond the scope of this study, but the inclusion of suspended sediment transport is an essential piece of sediment transport worth investigating in future research.

The other limitation that should be noted here is the simple channel configuration or fixed bank assumption. In this study, we used a straight channel with a non-erodible bank. In general, the channel width and curvature can vary in space and time and play an important role in river morphodynamics [46]. Nelson et al. investigated the response of riffle-pool morphology in a width-varying channel to the sediment supply condition, showing that the sediment supply has little effect on the riffle-pool features and that the width variation has a primary role in controlling the overall morphologies. The combination of planimetric channel geometry and sediment supply conditions is also necessary for future research.

This result is worth validating with experiments or field observations. Nelson and Morgan performed flume experiments on gravel bar dynamics under unsteady water discharge and constant sediment feed conditions. This condition satisfies the alternate bar dynamics in the presence of HBL. Because the duration of the hydrograph is much shorter than the morphodynamic time scale, the HBL is not evident in their experiment, but such an attempt will be a good dataset in the future. Furthermore, it is necessary to test this 2D calculation for other types of river morphology, such as bedforms [22,47] and meandering rivers [12], which have been extensively investigated in the context of the effect of sediment supply conditions.

\section{Conclusions}

We investigated the effect of sediment supply on the morphodynamics of free alternate bars in gravel-bed rivers in terms of the HBL concept proposed by Wong and Parker, using a 2D morphodynamic numerical model, iRIC-Nays2DH. Two-dimensional morphodynamic calculations regarding sand bar development were performed under cycled, single triangleshaped hydrographs with different sediment supply conditions, more specifically, constant and equilibrium feed conditions. The 1D morphodynamic perspective suggests that both feed conditions provide the same mobile-bed equilibrium downstream of the HBL. In contrast, it remains unclear whether the morphodynamic features at such a reach are identical even if the condition is extended to 2D cases, including complex bedforms such as alternate bars.

In the present condition, the simulated alternate bars develop outside the HBL, and characteristics of the alternate bars such as wavelength, bar height and migration speed are almost identical in both sediment feed conditions. This result suggests that the HBL concept is still valid for 2D cases, where the upstream sediment disturbance is difficult to propagate beyond the HBL, and eventually, has a negligible effect on the downstream morphological characteristics. We also changed the hydrograph characteristics, that is, the 
hydrograph duration and peak discharge were increased by a factor of 2, to understand the sensitivity of this result to the extreme change in the hydrograph from a practical perspective. The larger and longer hydrographs extend the length of the HBL, but the upstream sediment boundary condition does not affect the general characteristics of the downstream alternate bars. In summary, the findings regarding HBL [18] are almost valid for the dynamics of alternate bars developed beyond the HBL, that is, sediment disturbance at the upstream end has a negligible effect on the mobile-bed dynamic processes, including alternate bar formation and development downstream of the HBL.

The HBL is likely an effective temporal or spatial scale of the sediment disturbance (e.g., sediment pulse, sediment wave, gravel augmentation, etc.) in a single flood event, so this cannot be applied to larger-scale issues driven by long-term sediment increase/decline effects (e.g., dam construction). Moreover, this characteristic is highly dependent on the magnitude of the disturbance (size, shape, and texture) and hydraulic conditions. With more complex channel or bed configurations, some experimental or field observational validation will be necessary in future work.

Author Contributions: Conceptualization, H.D. and T.I.; methodology, H.D. and T.I.; software, T.I. and Y.S.; formal analysis, H.D.; investigation, H.D.; writing, H.D. and T.I.; visualization, H.D.; supervision, T.I. and Y.S.; funding acquisition, T.I. and Y.S. All authors have read and agreed to the published version of the manuscript.

Funding: This research was supported by a MEXT research grant, funded by Ministry of Education, Culture, Sports, Science and Technology.

Institutional Review Board Statement: Not applicable.

Informed Consent Statement: Not applicable.

Data Availability Statement: The data presented in this study are available on request from the corresponding author.

Conflicts of Interest: The authors declare no conflict of interest.

\section{References}

1. Padawangi, R.; Douglass, M. Water, water everywhere: Toward participatory solutions to chronic urban flooding in Jakarta. Pac. Aff. 2015, 88, 517-550. [CrossRef]

2. Yousefi, S.; Mirzaee, S.; Keesstra, S.; Surian, N.; Pourghasemi, H.R.; Zakizadeh, H.R.; Tabibian, S. Effects of an extreme flood on river morphology (case study: Karoon River, Iran). Geomorphology. 2018, 304, 30-39. [CrossRef]

3. Kazama, M.; Yamakawa, Y.; Yamaguchi, A.; Yamada, S.; Kamura, A.; Hino, T.; Moriguchi, S. Disaster report on geotechnical damage in Miyagi Prefecture, Japan caused by Typhoon Hagibis in 2019. Soils Found. 2021, 61, 549-565. [CrossRef]

4. Viero, D.P.; D'Alpaos, A.; Carniello, L.; Defina, A. Mathematical modeling of flooding due to river bank failure. Adv. Water Resour. 2013, 59, 82-94. [CrossRef]

5. Inoue, T.; Mishra, J.; Kato, K.; Sumner, T.; Shimizu, Y. Supplied sediment tracking for bridge collapse with large-scale channel migration. Water 2020, 12, 1881. [CrossRef]

6. Ohtsuka, S.; Sato, Y.; Yoshikawa, T.; Sugii, T.; Kodaka, T.; Maeda, K. Levee damage and revetment erosion by the 2019 Typhoon Hagibis in the Chikuma River, Japan. Soils Found. 2021, 61, 1172-1188. [CrossRef]

7. Visconti, F.; Camporeale, C.; Ridolfi, L. Role of discharge variability on pseudomeandering channel morphodynamics: Results from laboratory experiments. J. Geophys. Res. Earth Surf. 2010, 115, F4. [CrossRef]

8. Church, M. Channel morphology and typology. River Handb. 1994, 126-143.

9. Parker, G.; Wilcock, P.R.; Paola, C.; Dietrich, W.E.; Pitlick, J. Physical basis for quasi-univeral relations describing bankfull hy-draulic geometry of single-thread gravel bed rivers. J. Geophys. Res. Earth Surf. 2007, 112, F04005. [CrossRef]

10. Best, J. Anthropogenic stresses on the world's big rivers. Nat. Geosci. 2019, 12, 7-21. [CrossRef]

11. Nelson, P.A.; Brew, A.K.; Morgan, J.A. Morphodynamic response of a variable-width channel to changes in sediment supply. Water Resour. Res. 2015, 51, 5717-5734. [CrossRef]

12. Constantine, J.A.; Dunne, T.; Ahmed, J.; Legleiter, C.; Lazarus, E. Sediment supply as a driver of river meandering and floodplain evolution in the Amazon Basin. Nat. Geosci. 2014, 7, 899-903. [CrossRef]

13. Stähly, S.; Franca, M.J.; Robinson, C.T.; Schleiss, A.J. Sediment replenishment combined with an artificial flood improves river habitats downstream of a dam. Sci. Rep. 2019, 9, 1-8. [CrossRef] [PubMed]

14. Blum, M.D.; Roberts, H.H. Drowning of the Mississippi Delta due to insufficient sediment supply and global sea-level rise. Nat. Geosci. 2009, 2, 488-491. [CrossRef] 
15. Nittrouer, J.A.; Viparelli, E. Sand as a stable and sustainable resource for nourishing the Mississippi River delta. Nat. Geosci. 2014, 7, 350-354. [CrossRef]

16. Gaeuman, D.; Schmidt, J.C.; Wilcock, P.R. Complex channel responses to changes in stream flow and sediment supply on the lower Duchesne River, Utah. Geomorphology 2005, 64, 185-206. [CrossRef]

17. Morgan, J.A.; Nelson, P.A. Experimental investigation of the morphodynamic response of riffles and pools to unsteady flow and increased sediment supply. Earth Surf. Process. Landforms 2021, 46, 869-886. [CrossRef]

18. Wong, M.; Parker, G. One-dimensional modeling of bed evolution in a gravel bed river subject to a cycled flood hydrograph. J. Geophys. Res. Earth Surf. 2006, 111, F03018. [CrossRef]

19. An, C.; Cui, Y.; Fu, X.; Parker, G. Gravel-bed river evolution in earthquake-prone regions subject to cycled hydrographs and repeated sediment pulses. Earth Surf. Process. Landforms 2017, 42, 2426-2438. [CrossRef]

20. An, C.; Fu, X.; Wang, G.; Parker, G. Effect of grain sorting on gravel bed river evolution subject to cycled hydrographs: Bed load sheets and breakdown of the hydrograph boundary layer. J. Geophys. Res. Earth Surf. 2017, 122, 1513-1533. [CrossRef]

21. Nelson, P.A.; Morgan, J.A. Flume experiments on flow and sediment supply controls on gravel bedform dynamics. Geomorphology 2018, 323, 98-105. [CrossRef]

22. Venditti, J.G.; Nittrouer, J.A.; Allison, M.A.; Humphries, R.P.; Shurch, M. Supply-limited bedform patterns and scaling downstream of a gravel-sand transition. Sedimentology 2019, 66, 2538-2556. [CrossRef]

23. Shimizu, Y.; Takebayashi, H.; Inoue, T.; Hamaki, M.; Iwasaki, T.; Nabi, M. iRIC-Software: Nays2DH Solver Manual. 2014. Available online: https:/ / i-ric.org/en/ (accessed on 25 October 2021).

24. Nelson, J.M.; Shimizu, Y.; Abe, T.; Asahi, K.; Gamou, M.; Inoue, T.; Iwasaki, T.; Kakinuma, T.; Kawamura, S.; Kimura, I.; et al. The international river interface cooperative: Public domain flow and morphodynamics software for education and applications. Adv. Water Resour. 2016, 93, 62-74. [CrossRef]

25. Shimizu, Y.; Nelson, J.; Arnez, K.F.; Asahi, K.; Giri, S.; Inoue, T.; Iwasaki, T.; Jang, C.L.; Kang, T.; Kimura, I.; et al. Advances in computational morphodynamics using the International River Interface Cooperative (iRIC) software. Earth Surf. Process. Land. 2019, 45, 11-37. [CrossRef]

26. Iwasaki, T.; Nelson, J.; Shimizu, Y.; Parker, G. Numerical simulation of large-scale bed load particle tracer advection-dispersion in rivers with free bars. J. Geophys. Res. Earth Surf. 2017, 122, 847-874. [CrossRef]

27. Okitsu, T.; Iwasaki, T.; Kyuka, T.; Shimizu, Y. The Role of Large-Scale Bedforms in Driftwood Storage Mechanics in Rivers. Water 2021, 13, 811. [CrossRef]

28. Nagata, T.; Watanabe, W.; Yasuda, H.; Ito, A. Development of a meandering channel caused by the planform shape of the river bank. Earth Surf. Dynam. 2014, 2, 255-270. [CrossRef]

29. Yamada, T.J. Adaptation measures for extreme floods using huge ensemble of high-resolution climate model simulation in Japan. Summ. Rep. Elev. Meet. Res. Dialogue 2019, 28-30.

30. Hoshino, T.; Yamada, T.J.; Kawase, H. Evaluation for Characteristics of Tropical Cyclone Induced Heavy Rainfall over the Sub-basins in The Central Hokkaido, Northern Japan by 5-km Large Ensemble Experiments. Atmosphere 2020, 11, 435. [CrossRef]

31. Yamada, T.J.; Hoshino, T.; Suzuki, A. Using a massive high-resolution ensemble climate data set to examine dynamic and thermodynamic aspects of heavy precipitation change. At. Sci. Lett. 2021, 22, e1065. [CrossRef]

32. Francalanci, S.; Solari, L.; Toffolon, M.; Parker, G. Do alternate bars affect sediment transport and flow resistance in gravel-bed rivers? Earth Surf. Process. Land. 2012, 37, 866-875. [CrossRef]

33. East, A.E.; Logan, J.B.; Mastin, M.C.; Ritchie, A.C.; Bountry, J.A.; Magirl, C.S.; Sankey, J.B. Geomorphic evolution of a gravel-bed river under sediment-starved versus sediment-rich conditions: River response to the world's largest dam removal. J. Geophys. Res. Earth Surf. 2018, 123, 3338-3369. [CrossRef]

34. Ahammad, M.; Czuba, J.A.; Pfeiffer, A.M.; Murphy, B.P.; Belmont, P. Simulated dynamics of mixed versus uniform grain size sediment pulses in a gravel-bedded river. J. Geophys. Res. Earth Surf. 2021, 126, e2021JF006194. [CrossRef]

35. Sutherland, D.G.; Ball, M.H.; Hilton, S.J.; Lisle, T.E. Evolution of a landslide-induced sediment wave in the Navarro River, California. GSA Bull. 2002, 114, 1036-1048. [CrossRef]

36. Facchini, M.; Bertoldi, W.; Boes, R.; Vetsch, D.A.; Siviglia, A. Effects of natural and anthropogenic repeated water and sediment inputs to gravel-bed rivers: A numerial study. AGU Fall Meet. Abstr. 2018, 2018, EP31A-05.

37. Rachelly, C.; Friedl, F.; Boes, R.M.; Weitbrecht, V. Morphological response of channelized, sinuous gravel-bed rivers to sediment replenishment. Water Resour. Res. 2021, 57, e2020WR029178. [CrossRef]

38. Schmidt, J.C.; Wilcock, P.R. Metrics for assessing the downstream effects of dams. Water Resour. Res. 2008, 44, W04404. [CrossRef]

39. Morgan, J.A.; Nelson, P.A. Morphodynamic modeling of sediment pulse dynamics. Water Resour. Res. 2019, 55, 8691-8707. [CrossRef]

40. Lisle, T.E.; Cui, Y.; Parker, G.; Pizzuto, J.E.; Dodd, A.M. The dominance of dispersion in the evolution of bed material waves in gravel-bed rivers. Earth Surf. Proc. Land. 2001, 26, 1409-1420. [CrossRef]

41. Lanzoni, S.; Tubino, M. Grain sorting and bar instability. J. Fluid Mech. 1999, 393, 149-174. [CrossRef]

42. Blom, A.; Parker, G. Vertical sorting and the morphodynamics of bed form-dominated rivers: A modeling framework. J. Geophys. Res. Earth Surf. 2004, 109, F02007. [CrossRef]

43. Takebayashi, H.; Egashira, S. Non-equilibrium characteristics of bar geometry on bed with non-uniform sediment. J. Hydrosci. Hydraul. Eng. 2008, 26, 1-14. 
44. An, C.; Moodie, A.; Ma, H.; Fu, X.; Zhang, Y.; Naito, K.; Parker, G. Morphodynamic model of the lower Yellow River: Flux or entrainment form for sediment mass conservation? Earth Surf. Dynam. 2018, 6, 989-1010. [CrossRef]

45. Chen, Y.; Nakatsugawa, M.; Ohashi, H. Research of Impacts of the 2018 Hokkaido Eastern Iburi Earthquake on Sediment Trasnport in the Atsuma River Basin Using the SWAT Model. Water 2021, 13, 356. [CrossRef]

46. Zolezzi, G.; Luchi, R.; Tubino, M. Modeling morphodynamic processes in meandering rivers with spatial width variations. Rev. Geophys. 2012, 50, 1-24. [CrossRef]

47. Kleinhans, M.; Wilbers, A.W.E.; de Swaaf, A.; Van den Berg, J.H. Sediment supply-limited bedforms in sand-gravel bed rivers. J. Sediment. Res. 2002, 72, 629. [CrossRef] 